\title{
Soya isoflavones, genistein and daidzein, induce differential transcriptional modulation in the ovary and testis of zebrafish Danio rerio
}

\author{
Carmen Sarasquete*, María Úbeda-Manzanaro, Juan B. Ortiz-Delgado \\ Instituto de Ciencias Marinas de Andalucía, Consejo Superior de Investigaciones Científicas (ICMAN-CSIC), \\ Campus Universitario Rio San Pedro, Apdo oficial, 11510 Puerto Real, Cádiz, Spain
}

\begin{abstract}
Most research into the effects of phytochemical isoflavones has focussed on endocrine disruptions, and especially on oestrogenic imbalances; however, little is known about their effects on other molecular signals such as transcriptional coregulators and choriolytic enzymatic pathways, which are also important in reproductive processes. In male and female zebrafish Danio rerio, the soya isoflavones genistein and daidzein (provided at $10 \mathrm{mg} \mathrm{l}^{-1}$ for $15 \mathrm{~d}$ ) modulated the basal expression levels of oestrogen receptor transcripts (ER $\beta$ ) in variable and differential ways. Exposure to genistein resulted in decreased levels of ER $\beta$ in the zebrafish ovary; conversely, this isoflavone increased the basal expression levels of the hatching enzyme (HE1) in both gonads. On the other hand, daidzein increased the basal expression levels of the bromodomain testisspecific gene (BRDT) in the male gonad, but not in the ovary. Both isoflavones also differentially modulated (up-down regulations) the basal expression patterns of the 3 molecular signals studied in other regions of the body (e.g. head, digestive system, skeletal musculature). Despite all these transcriptional imbalances, neither of the phytoestrogens modified gonadal histomorphology or the baseline histochemical pattern of proteins, carbohydrates and glycoconjugates distributed in either the vitelline structures or in the developing and maturing germ cells of Danio rerio.
\end{abstract}

KEY WORDS: Bromodomain-testis · Hatching enzyme · Oestrogen receptor · Gonads · Isoflavones · Histochemistry $\cdot$ Transcripts $\cdot$ Zebrafish

\section{INTRODUCTION}

Fish exposure to different endocrine disrupting compounds (EDCs), both chemical and phytochemi$\mathrm{cal}$, can occur through contaminated waste in surface water and coastal areas. In particular, phytoestrogens (flavonoids and non-flavonoids) originating from various anthropogenic activities (e.g. livestock, agriculture, aquaculture), with variable levels of isoflavones, metabolites and other phytochemicals, have been recorded in aquatic environments ranging from nanomolars to $0.20 \mathrm{mg} \mathrm{l}^{-1}$ (Kiparissis et al. 2001, Spengler et al. 2001, Rocha et al. 2013, Rearick et al. 2014). In terms of hormonal modulation and endocrine disruption in fish, it has been widely noted that all stages of

${ }^{*}$ Corresponding author: carmen.sarasquete@csic.es development and life history, from embryo to adulthood, constitutively express the majority of mRNA transcripts related to hatching, reproduction and growth. All these crucial processes are modulated through oestrogen: apoptotic, proliferative and epigenetic signaling pathways, among others. It has also been reported that all fish life stages are sensitive and respond differently to both chemical and phytochemical EDCs (Pelissero et al. 1991, Kiparissis et al. 2003, Segner et al. 2003, Sassi-Messai et al. 2009, Schiller et al. 2013, Sarasquete et al. 2017, 2018a,b, 2019).

Phytochemical isoflavones act as selective oestrogen receptor modulators (SERMs), that is, as ligands (agonists or antagonists) of oestrogen receptors (ERs). This function depends on the coactivators and

() The authors 2020. Open Access under Creative Commons by Attribution Licence. Use, distribution and reproduction are unrestricted. Authors and original publication must be credited. 
corepressors present in the cells due to cross-talks between ERs and other transcription factors, and varies according to the basal levels of endogenous oestrogens (An et al. 2001, Setchell et al. 2005, Lecomte et al. 2017, Xiao et al. 2018). Unlike mammals, many species of fish harbor 3 ER genes. In zebrafish, the genes of these oestrogen receptors are designated ER1 (ER $\alpha)$, ER2b (ER 1$)$ and ER2a (ER $\beta 2)$. Basal constitutive levels of ERs (ER $\alpha$ and $\beta s$ ) are expressed at all life history stages of fish and show highly variable levels of transcription in both reproductive and non-reproductive organs. In addition, ERs have different binding profiles than natural and exogenous ligands, which vary according to development and life history stage. ERs also show selective and differential distribution in the organs and tissues of adult fish and also differ between males and females, as has been described extensively in zebrafish and other species (Bardet et al. 2002, Menuet et al. 2002, 2004, Chandrasekar et al. 2010, Lu et al. 2017).

Isoflavones (genistein, daidzein) are unique, in that these phytochemicals have a higher and more selective binding affinity for ER $\beta$ than for ER $\alpha$. Most of the isoflavonoid phytoestrogens, which act as SERMs, also show a higher binding affinity for ER $\beta$ compared to many chemical endocrine disruptors and in contrast to the endogenous ligand (17 $\beta$-oestradiol), which in mammals shows a very high binding affinity for both receptors (ER $\alpha$ and $E R \beta)$. In fish, in contrast to many higher vertebrates, a lower binding affinity of ERs (ER $\alpha$ and $\beta s$ ) for the natural ligand, oestradiol, has also been demonstrated (Kuiper et al. 1998, Miyahara et al. 2003, Setchell et al. 2005, Patisaul \& Adewale 2009, Nelson \& Habibi 2013). Interestingly, in a recent in vitro study in zebrafish, genistein exhibited higher binding affinity for $E R \alpha$ than for ER $\beta 1$ or $\beta 2$ (Sassi-Messai et al. 2009). In a different study with medaka Oryzias latipes and zebrafish embryos exposed to different doses of genistein, different and variable response patterns were described in the transcription levels of the ER $\alpha$ and ER $\beta$ receptors which also varied by species and with the phytoestrogen dose (Schiller et al. 2013). Due to the highly conserved sequences and very high structural homologies (DNA-binding domain [DBD] and ligand binding domain [LBD]) between ERs in humans $(E R \alpha, \beta)$ and zebrafish $(E R \alpha, \beta 1, \beta 2)$ (Menuet et al. 2002, Chandrasekar et al. 2010, Schaaf 2017, Asnake et al. 2019), and also because of the higher expected affinity of genistein and daidzein for ER $\beta$, in this work we analyzed the levels of expression of ER $\beta$ transcripts $(\beta 2+\beta 1$ as a whole $)$ in zebrafish, as has been done in studies with other fish species (Legler et al. 2000, Arukwe et al. 2008, Reyhanian et al. 2014, Sarasquete et al. 2017, 2018a, 2019).

In zebrafish and other fish species, reduced fertilisation, decreased hatching rates and reproductive imbalances have been described as the most common endocrine disorders (and/or the most toxic effects) that can be induced by endogenous factors (e.g. sex hormones) and by isoflavonoid phytoestrogens (Bennetau-Pelissero et al. 2001, Kiparissis et al. 2003, Kim et al. 2009, Sassi-Messai et al. 2009, Schiller et al. 2013, Sarasquete et al. 2018a). Hatching enzymes (HEs) are composed of the astacin-protease domain, and these zinc-dependent metalloproteases possess the ability to digest the envelope of the egg or chorion. While HEs (e.g. choriolysins) digest the egg's protein envelope to facilitate hatching, alveoline, which is a metalloprotease released from cortical alveoli of early vitellogenic oocytes, induces reassembly of choriogenins to harden the egg envelope at the time of fecundation. Some metalloproteases that are present in gametes are essential to ensure reproductive success, by facilitating the passage and penetration of sperm during fertilisation (Yamagami, 1996, Sano et al. 2008, Kawaguchi et al. 2012, Shibata et al. 2012, Nagasawa et al. 2015, Chakraborty et al. 2017).

Phytoestrogenic isoflavones have also been associated with the developmental processes of proliferation, apoptosis and sexual differentiation, as well as with chromatin remodelling, DNA repair and epigenetic mechanisms (Patisaul \& Adewale 2009, Lecomte et al. 2017, Xiao et al. 2018). In mammals, the bromodomain testis-specific gene (BRDT) is an essential factor during spermatogenesis and for male fertility. It is widely known that BRDT proteins bind to hyperacetylated chromatin during sperm elongation, and that these bromodomains recruit the machinery to remove acetylated histones which are replaced by protamines. In addition, bromodomain and extraterminal domain (BET) proteins can also maintain this structural role and participate in chromatin remodelling during oogenesis (Paillisson et al. 2007, Berkovits \& Wolgemuth 2013, Bao \& Bedford 2016, Taniguchi 2016). In fish, the role of the BRDT gene and proteins, which play a key role in hatching, development and differentiation, as well as embryogenesis and gametogenesis of males and females, is much less known and appears to be much more complex and variable than in other vertebrates (Úbeda-Manzanaro et al. 2016, Sarasquete et al. 2018a). This complexity is potentially due to different strategies and reproductive behaviors, environmental and hormonal sensi- 
tivity or to the remarkable neuroendocrine and sexual plasticity of the fish (Devlin \& Nagahama 2002, Segner et al. 2003, Piferrer \& Guiguen 2008, Ribas et al. 2017).

The zebrafish Danio rerio is a small tropical freshwater cyprinid and an experimental model widely accepted in different fields of biomedical and animal research. The existence of a syntenic relationship between the human and zebrafish genomes (www. ensembl.org, D. rerio, genome release Zv9genomes) has been demonstrated, and both genomes can be compared (Mayden et al. 2007, Howe et al. 2013). In addition, due to its well-known embryogenesis and larval development, easy reproduction, sexual dimorphism, high fertility and short life cycle, all stages of zebrafish development and life history have been used in research disciplines such as embryogenesis, larval development, sexual differentiation, reproduction, environmental control, endocrine disruption and ecotoxicology (Selman et al. 1993, Kimmel et al. 1995, Segner 2009, Santos et al. 2017, Wang et al. 2019, and many others).

In the present study, our objective was to provide substantial evidence of the suitability of using a double transcriptional and cellular approach to evaluate the effects of 2 phytoestrogenic isoflavones. This research is mainly focussed on oestrogenic and choriolytic signals and transcriptional coregulation pathways. For this purpose, basal expression patterns and transcriptional variations of 3 molecular signals (ER $\beta$ [ $=\beta 1+\beta 2$, as a whole], HE1 and BRDT) were analysed in different organs and tissues (gonads, head portion, skeletal musculature and digestive system) of male and female zebrafish exposed to a non-toxic concentration of soya isoflavones (daidzein and genistein). Furthermore, in both gonads the histomorphological and histochemical basal patterns and possible cellular alterations induced by both phytochemicals were examined.

\section{MATERIALS AND METHODS}

\subsection{Biological samples}

Adult male and female zebrafish Danio rerio (genotype $A B / T u ̈ b i n g e n)$ were maintained at the Institute of Marine Sciences of Andalusia (ICMAN-CSIC, Puerto Real, Spain). The facilities of ICMAN-CSIC are in compliance with the European Convention for the Protection of Animals used for Experimental and Scientific Purposes, and the fish were approved for experimentation by the Ministry of Agriculture and
Fisheries (REGA-ES110280000311) in accordance with current EU (Directive 2010/63/EU) and Spanish legislation. The experimental procedure (projects AGL2014-52906-R ${ }_{i}$ RTI2018-0939-B-100) was approved by the Spanish National Research Council (CSIC) Ethics Committee, and by the Spanish Competent Authority, Junta de Andalucía (no. 09-7-15278, RD53/2013; 832/2019).

\subsection{Toxicity tests}

Genistein (C15H10O5, LC Laboratories) and daidzein (C15H10O4, LC Laboratories) were dissolved in ethanol to make up 20 and $5 \mathrm{mM}$ stock solutions, respectively, and then kept in the dark at $4{ }^{\circ} \mathrm{C}$ until use. Mixed stock of 3-4 mo old male and female zebrafish $D$. rerio (AB) were kept in an automatic flowthrough system supplied with recirculating filtered water at $27-28^{\circ} \mathrm{C}$ under $14 \mathrm{~h}$ light: $10 \mathrm{~h}$ dark photoperiod cycle, keeping the physical-chemical parameters stable (Zebrafish Housing System from Aquatic Habitats B26U-2-A). For experimental trials, fish $(\mathrm{n}=60$; 1:1 sex ratio) with a standard total length between 3.5 and $4.0 \mathrm{~cm}$ were randomly distributed in $2.5 \mathrm{l}$ glass tanks $\left(\mathrm{n}=6\right.$ group $\left.^{-1}\right)$ and fed daily with commercial pellets. Duplicates of controls (with and without ethanol) and triplicates of the experimental groups were used and analysed. For exposure tests to both isoflavones, a nominal concentration of $10 \mathrm{mg} \mathrm{l}^{-1}$ was chosen, taking into account toxicity parameters and non-harmful effects or responses that were calculated in zebrafish embryos and early larvae (Sarasquete et al. 2018a). During the 2 wk experimental period, under semi-static tests, $50 \%$ of the water was renewed daily with the corresponding proportion of freshly prepared stock solutions of both isoflavones. At the end of the experimental tests (15 d), all fish were anesthetised with an overdose of phenoxyethanol, and samples of the different organs and tissues were taken for molecular analysis (gonads, head, digestive system, skeletal musculature) and for histologicalhistochemical studies (ovary, testis), following similar procedures and standardised technical protocols conducted in recent research on zebrafish and other fish species (Sarasquete et al. 2017, 2018a, 2019).

\subsection{Nucleic acid extraction and quantification of mRNA expression levels}

For molecular analysis, triplicate samples were preserved into RNAlater (Sigma-Aldrich) for $24 \mathrm{~h}$ at 
$4^{\circ} \mathrm{C}$ and stored at $-80^{\circ} \mathrm{C}$. Total RNA was isolated from different organs and tissues (gonads, head, digestive system and musculature) using a RNeasy ${ }^{\circledR}$ Micro kit (Qiagen). Genomic DNA was removed via DNase digestion at $37^{\circ} \mathrm{C}$ for $30 \mathrm{~min}$. Total RNA quality was verified (Bioanalyzer 2100; Agilent Technologies) and concentration was assessed by spectrophotometry $\left(A_{260} / A_{280} \mathrm{~nm}\right)$. For cDNA synthesis, total RNA (500 ng) was utilised for reverse transcription using a qScript ${ }^{\mathrm{TM}}$ cDNA Synthesis kit (BioRad). Realtime analysis was performed (Mastercycler ep gradient S Realplex2). Each reaction was carried out in triplicate with a mixture containing each of the specific primer pair (Table 1), cDNA ( 10 ng), and $5 \mu \mathrm{l}$ iTaq $^{\mathrm{TM}}$ Universal SYBR ${ }^{\circledR}$ Green SuperMix (BioRad). Relative gene quantification was performed using the method of Pfaffl (2001), and results were normalised to elongation factor 1 alpha 1 (eEf1a1) and 18S rRNA, as recently described by Sarasquete et al. (2018a, 2019).

\subsection{Statistical analysis}

Temporal differences for each of the gene expression patterns and both treatments were tested by 1-way ANOVA performed after a base 10 logarithmic transformation to meet requirements for the parametric test. Normality was checked using Shapiro-Wilk's test and homogeneity of variances with the Levene's test. Tukey's post hoc test was used to identify significantly different groups. Differences were considered statistically significant at $\mathrm{p}<0.05$. Statistical analyses of data from
qPCR were performed using SPSS v.23.0.0.0 software (IBM).

\subsection{Histological and histochemical approaches}

Samples of both gonads were fixed in $4 \% \mathrm{v} / \mathrm{v}$ neutral formaldehyde ( $\mathrm{pH}$ : 7.2) in sodium phosphate buffer $(0.1 \mathrm{M})$ and embedded in paraffin wax. In the serial sections $(5-6 \mu \mathrm{m})$, histomorphological staining techniques were used, such as Haematoxylin-eosin and Haematoxylin-VOF (Light green, Orange G, Acid Fuchsin) and Type III-G.S (Sarasquete \& Gutierrez 2005). To analyse the cellular distribution of carbohydrates and proteins, several histochemical techniques were performed: PAS and diastase-PAS (neutral-glycoconjugates, glycoproteins, glycogen); Alcian Blue at pH 2.5, 1, and 0.5 (carboxylated and sulphated glycoconjugates); Mercury-Bromophenol Blue/Hg-BFB (general proteins); Ninhydrin-Schiff (proteins rich in lysine, $\mathrm{NH}_{2}$ ); Ferric-Ferricyanide/Thioglycollate reduction (cysteine and cystine; -SH and -S-S groups); 1,2-Naftoquinone-4-sulphonate sodium/NQS (arginine); P-dimethylaminobenzaldehyde/DMAB-nitrite (tryptophan); and Hg-sulphate-sulphuric acidsodium nitrate/Millon reaction (tyrosine). For the characterization of different glucidic residues bound to the glycoconjugates, several peroxidaseHPR-conjugated lectins were used, extracted from Canavalia ensiformes (ConA; Man/Glc), Ulex europaeus (UEA-I; Fuc), Triticum vulgaris (WGA; $\beta$ GlcNAc $>>$ NeuNAc/sialic acids/NANA), Glycine $\max \left(\mathrm{SBA}_{i} \alpha / \beta\right.$ GalNAc) and Sambucus nigra

Table 1. Primer sequences, amplicon length $(\mathrm{AE})$, annealing temperature $(T)$, efficiency $(E)$ and gene reference in the experiment of zebrafish exposed to isoflavones

\begin{tabular}{|c|c|c|c|c|c|}
\hline Target & Sequence $\left.\left(5^{\prime}-3\right)^{\prime}\right)$ & $\mathrm{AE}(\mathrm{bp})$ & $T\left({ }^{\circ} \mathrm{C}\right)$ & $E^{\mathrm{a}}$ & $\begin{array}{l}\text { GeneBank } \\
\text { accession no. }\end{array}$ \\
\hline 18S sRNA & $\begin{array}{l}\text { GAA CGC CAC TTG TCC CTC TA } \\
\text { ATG GCC GTT CTT AGT TGG TG }\end{array}$ & 130 & 60 & 2.0704 & NR_145818.1 \\
\hline eEF1a1 & $\begin{array}{l}\text { TCT TCC ATC CCT TGA ACC AG } \\
\text { CCT ACA GCG AAA CAC GTT CA }\end{array}$ & 134 & 60 & 2.0234 & AY422992.1 \\
\hline $\mathrm{ER} \beta$ & $\begin{array}{l}\text { GGA TTC AAG CCA TTG TCA CC } \\
\text { CCT GCA GGA TTC AAG GTT TC }\end{array}$ & 130 & 60 & 2.0112 & AJ275911.3 \\
\hline HE1a1 & $\begin{array}{l}\text { AGG AGC GAT CGT GAC CAG TA } \\
\text { GCC GTT TTT CCA TAG TGC AT }\end{array}$ & 140 & 60 & 2.0396 & NM_001045174.2 \\
\hline BRDT & $\begin{array}{l}\text { CCA GCA AAC CGT GAC CGT CAT CC } \\
\text { GGC AGA AGG TGT CGT AGT GTC TGC }\end{array}$ & 130 & 60 & 1.9952 & NM_001305664.1 \\
\hline
\end{tabular}


(SNA; Neur5Aco2; sialic acids/NANA). Lectin concentrations ranged between 15 and $30 \mathrm{\mu g} \mathrm{ml}^{-1}$, and specific sugar inhibitors were also used. The peroxidase activity was visualised with 3,3'diaminobenzidine tetra hydrochloride/DAB and hydrogen peroxide $(0.05 \%)$. All techniques were performed according to Pearse (1985), and following previously standardised techniques and protocols (Sarasquete et al. 2002). All reagents were purchased from Sigma-Aldrich.

\section{RESULTS}

ER $\beta, H E 1$ and BRDT were expressed in variable and differential ways in both male and female zebrafish gonads as well as in the different body regions studied. The highest levels of constitutive basal expression of ER $\beta$ were recorded in the testis $>>$ digestive system $>$ ovary $=$ musculature $=$ head portion (Fig. 1A). In parallel, HE1 transcripts showed the following basal expression patterns: testis $>>>$ ovary $>$ skeletal musculature $>$ head $=$ digestive system (Fig. 1B). Furthermore, the basal levels of the BRDT transcripts were differentially expressed as follows: ovary $>>$ testis $>$ head $=$ musculature $>$ diges tive system (Fig. 1C).

The isoflavone genistein down-regulated the transcript levels of ER $\beta$ in the ovary and digestive system, and up-regulated ER $\beta$ levels in the skeletal musculature. Daidzein increased ER $\beta$ expression levels in the head portion and skeletal musculature. Nevertheless, no significant differences were observed in the basal expression levels of ER $\beta$ in the testes due to the effect of both isoflavones. On the other hand, baseline transcription levels of $\mathrm{HE}$, which were expressed at a higher level in the testes than in the ovaries, were up-regulated in both gonads due to genistein exposure. Daidzein only increased the levels of HE1 expression in skeletal musculature. This isoflavone increased transcription levels of BRDT in the testes, and

Fig. 1. Relative expression levels of (A) oestrogen receptor transcript (ER $\beta$ ), (B) hatching enzyme (HE1) and (C) bromodomain testis-specific gene (BRDT) in controls and male and female zebrafish exposed to both isoflavones. Bars: means $\pm \mathrm{SE}(\mathrm{n}=6 \times 3)$ of the relative expression level of the gene for controls, and treatment with $10 \mathrm{mg} \mathrm{l}^{-1}$ daidzein and $10 \mathrm{mg} \mathrm{l}^{-1}$ genistein. Asterisks: significant differences between treatment group controls. Lowercase letters: significant differences between the mean values of each organ for the same treatment (1: control; 2: daidzein; 3: genistein)
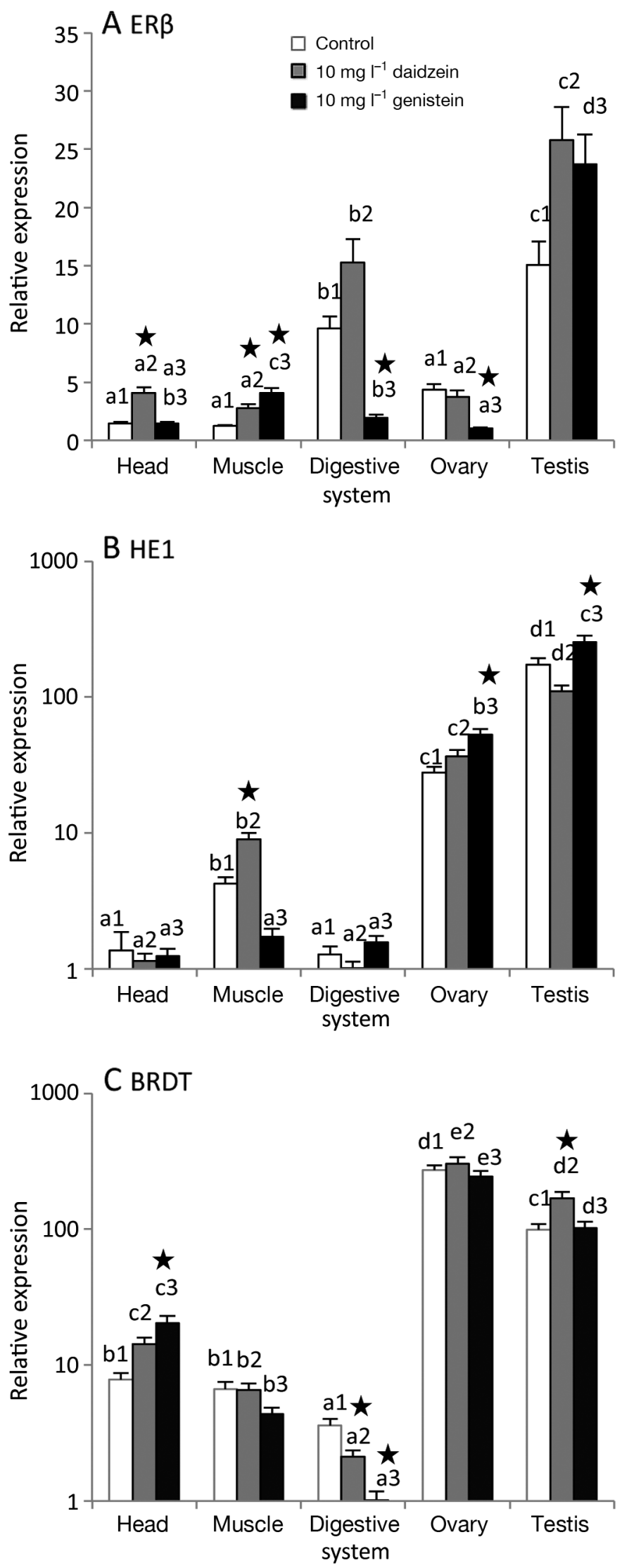
these bromodomains were down-regulated in the digestive system. Finally, genistein up-regulated the expression levels of BRDT in the head portion, and these BRDT transcripts were down-regulated in the digestive system (Fig. 1).

As illustrated briefly in Fig. 2, the male and female zebrafish gonads were in advanced stages of gametogenesis. Thus, in the ovaries the presence of pre-vitellogenic basophilic oocytes and acidophilic oocytes was observed in the different stages of vitellogenesis, as well as the presence of some residual post-ovulatory follicles. In the testes, all the cells of the spermatogenic line were also present, distributed along the seminiferous tubules and contained cysts of spermatogonia, spermatocytes and spermatids in the testicular epithelia, as well as groups of spermatozoa released in the lumen of the tubules and seminiferous ducts. In the ovary, the cortical alveoli, which appeared at the periphery of the early vitellogenic oocytes, contained a moderate amount of carboxylated glycoconjugates and abundant neutral glycoproteins. As vitellogenesis progressed, acidophilic yolkgranules and the characteristic zona radiata were evident, and both structures contained abundant proteins rich in all amino acids studied along with neutral glycoproteins. The yolk granules showed a remarkable staining affinity for all the lectins studied (ConA, UEA, WGA, SBA, SNA), which indicates great richness in glycoconjugates containing different sugar residues, such as mannose/glucose, fucose, N-acetyl galactosamine/glucosamine and sialic acids, whereas cortical alveoli and the zona radiata showed specific higher affinity for the WGA lectin ( $\beta$-GlcNAc; NeuNAc). In the testes, most spermatogenic cells contained proteins rich in all amino acids studied, with marked increases in proteins rich in basic amino acids (i.e. arginine and lysine) and cysteine, especially in the spermatozoa. Most sugar residues bound to glycoconjugates increased, especially in spermatids and spermatozoa, as summarised in Table 2 .

Finally, no histomorphological-histochemical modifications were observed in either the male or female gonads after exposure to both soya isoflavones. In addition, over the course of the 2 wk experiment, no significant variations were detected in the biometric parameters of the 3-4 mo old male and female zebrafish exposed to both phytoestrogens (average weights between $0.38 \pm 0.03$ and $0.40 \pm 0.02 \mathrm{~g}$ ) compared to the controls groups, and no mortalities were recorded.

\section{DISCUSSION}

The present study showed variable and differential basal expression patterns in the 3 genes studied (ER $\beta, H E 1$, and BRDT) according to sex and the different organs and tissues of the zebrafish that were analysed. Interestingly, basal constitutive transcript patterns for the 3 genes were quite unexpected in both gonads. In fact, for both transcript patterns (ER $\beta$ and HE1), higher basal expression levels were recorded in the testes than in the ovaries, while basal expression levels of BRDT were higher in the ovaries than in the testes. Similarly, exposure to the same non-toxic dose of both soya isoflavones (genistein and daidzein, at $10 \mathrm{mg} \mathrm{l}^{-1}$ for $2 \mathrm{wk}$ ) induced differential and variable transcriptional responses depending on the organs and tissues analysed (e.g. gonads, head, digestive system and skeletal musculature) and according to sex and the type of isoflavone provided. Most genes involved in reproduction, hatching, development and epigenetic processes (e.g. oestrogens and receptors, choriogenins, HEs, apoptotic and epigenetic markers, bromodomains) express constitutively at high or moderate levels in the

Fig. 2. Histological sections of zebrafish ovary and testis. (A) Asynchronous oogenesis showing several basophilic previtellogenic oocytes (arrowheads), an early vitellogenic oocyte with a still intense basophilia (RNA) and with the presence of the first cortical alveoli in the peripheral cytoplasm. There is also a section of a final vitellogenic oocyte containing acidophilic yolk granules and the characteristic zona radiata. (B) Pre-vitellogenic basophilic oocytes and intermediate acidophilic vitellogenic oocytes containing abundant cortical alveoli. (C) Different stages of vitellogenesis showing an early vitellogenic oocyte with numerous cortical alveoli, and an advanced vitellogenic oocyte with abundant acidophilic yolk granules. (D) Detail of an oocyte in the final stage of vitellogenesis containing numerous acidophilic yolk granules (orange-G affinity) and abundant cortical alveoli, as well as empty vacuoles or lipid globules. The onset of coalescence or fusion of the yolk is highlighted. The characteristic zona radiata is observed with its cellular or follicular outer layer, as well as the presence of post-ovulatory residual follicles. (E,F) In the 2 testicular sections, the different types of germ cell cysts (spermatogonia, spermatocytes, spermatids and spermatozoids) are distributed along the seminiferous epithelium, with a synchronous development of the germ cells and several groups of spermatozoids that are found regularly and are released in the lumen of the seminiferous tubules and in the system of efferent ducts. CA: cortical alveoli; FL: follicular layer; LG: lipid globules; PO: previtellogenic oocytes; PF: post-ovulatory follicles; VO: vitellogenic oocytes; YG: yolk granules; ZR: zona radiata; SZ: spermatozoids. Scale bars in (A,D) $100 \mu \mathrm{m}$; (B,C) $50 \mu \mathrm{m}$; $(\mathrm{D}, \mathrm{F}) 25 \mu \mathrm{m}$. Ovarian sections: Haematoxylin-VOF. Testicular sections: Haematoxylin-eosin (E); Haematoxylin-VOF (F) 

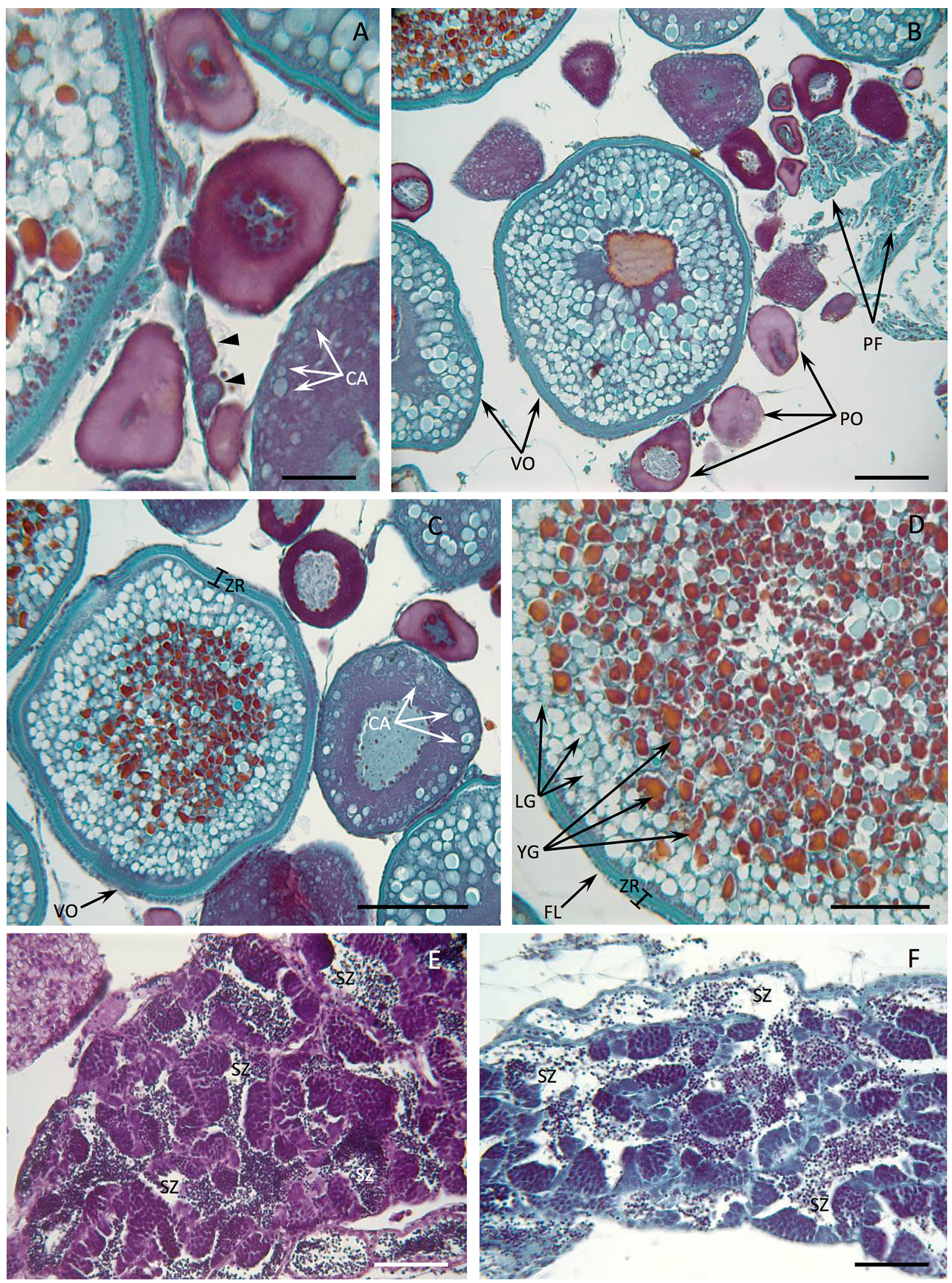
Table 2. Histochemical characteristics in gonads of zebrafish controls and exposed to isoflavones. Semi-quantitative data determined by 4 independent observers, showing different staining intensities and affinities to biological compounds, from negative (-) to weak, moderate and strongly positive (from 1+ to 3+). CA: cortical alveoli; YG: yolk granules; ZR: zona radiata; Spg: spermatogonia; Spc: spermatocyte; Spd: spermatid; Spz: spermatozoid

\begin{tabular}{|c|c|c|c|c|c|c|c|c|}
\hline \multirow[t]{2}{*}{ Demonstrated compounds } & \multirow{2}{*}{$\begin{array}{l}\text { Previtellogenic } \\
\text { cytoplasm }\end{array}$} & \multicolumn{3}{|c|}{ Vitellogenic oocytes } & \multirow[t]{2}{*}{ Spg } & \multirow[t]{2}{*}{$\mathrm{Spc}$} & \multirow[t]{2}{*}{ Spd } & \multirow[t]{2}{*}{$\mathrm{Spz}$} \\
\hline & & CA & YG & ZR & & & & \\
\hline \multicolumn{9}{|c|}{ PAS } \\
\hline \multicolumn{9}{|c|}{ Neutral glycoconjugates/GCGs } \\
\hline Glycogen/Glycolipids & $2+$ & $2+$ & $2+$ & $3+$ & $2+$ & + & + & + \\
\hline \multicolumn{9}{|l|}{ Diastase-PAS } \\
\hline Glycogen & + & $2+$ & + & $3+$ & + & +- & + & + \\
\hline \multicolumn{9}{|l|}{ AA 2.5} \\
\hline Carboxylated GCGs & +- & $2+$ & +- & +- & + & + & $2+$ & $3+$ \\
\hline \multicolumn{9}{|l|}{ AA $0.5 / 1$} \\
\hline Sulphated GCGs & +- & +- & - & - & - & - & - & - \\
\hline \multicolumn{9}{|l|}{ Bromophenol-blue } \\
\hline General proteins & $2+$ & + & $2+$ & $3+$ & + & + & $2+$ & $3+$ \\
\hline Lysine rich proteins & $2+$ & + & $2+$ & + & + & + & $2+$ & $3+$ \\
\hline Arginine rich proteins & + & + & $2+$ & $2+$ & + & + & $2+$ & $3+$ \\
\hline Cysteine-SH- & + & + & + & $2+$ & + & + & $2+$ & $3+$ \\
\hline Cystine-S-S- & + & + & + & $2+$ & + & + & $2+$ & $2+$ \\
\hline Tyrosine rich proteins & + & +- & + & $2+$ & + & + & + & $2+$ \\
\hline Tryptophan rich proteins+ & + & +- & + & + & +- & +- & +- & +- \\
\hline \multicolumn{9}{|l|}{ ConA } \\
\hline Man/Glc & + & - & +- & +- & - & - & + & + \\
\hline \multicolumn{9}{|l|}{ UEA-I } \\
\hline $\begin{array}{l}\text { L-Fuc } \alpha 1 \text {, } \\
\text { WGA }\end{array}$ & + & - & +- & +- & - & - & + & + \\
\hline$\beta$-GINAc $>>$ NeuNAc & + & + & + & + & - & - & + & $2+$ \\
\hline \multicolumn{9}{|l|}{ SBA } \\
\hline$\alpha / \beta$ GalNac & + & + & + & + & - & - & + & + \\
\hline \multicolumn{9}{|l|}{ SNA } \\
\hline Sialic acids/ & & & & & & & & \\
\hline Neu5Ac 2 2/NANA & + & + & + & + & - & - & + & $2+$ \\
\hline
\end{tabular}

gonads and during the early stages of development and life, as has been reported in different species of fish including zebrafish (Segner et al. 2003, Chandrasekar et al. 2010, Úbeda-Manzanaro et al. 2016, Sarasquete et al. 2018a, González-Rojo et al. 2019). All these findings corroborate the maternal origin of mRNA transcripts and their transfer to the progeny, since the oocyte is the starting point of a new generation. As reviewed by Arukwe \& Goksøyr (2003), most of the machinery for DNA and protein synthesis necessary for the developing embryo is performed autonomously by fertilised oocytes.

In the present study, as expected, ERs (e.g. ER $\beta$ ) were expressed constitutively and differentially in most organs and tissues involved in reproductive and non-reproductive functions, displaying higher transcript levels for ER $\beta$ in the testes than in the ovaries. Several authors have also pointed out that the 3 ERs $(\alpha, \beta 1, \beta 2)$ overlap and are expressed mainly in the brain, pituitary, liver and gonads of zebrafish, displaying much lower basal expression levels for the ERs in the ovaries than in the testes. Furthermore, zebrafish males and females show a differential and opposite binding affinity for the different endogenous and exogenous ligands, indicating a sexually divergent mechanism and sex-specific control of ERs (Menuet et al. 2002, 2004, Chandrasekar et al. 2010, Lu et al. 2017, Schaaf 2017). Interestingly, some remarkable differences were observed in zebrafish compared to other species of fish, such as the hermaphrodite seabream Sparus aurata, which showed higher basal expression levels of ER $\beta$ in the ovaries and for ER $\alpha$ in the testes. In addition, very high basal expression levels have also been described for the 3 ERs $(E R \alpha, \beta s)$ in seabream testes, which corroborates the crucial role of oestrogens and their receptors for reproduction in both sexes. In parallel, in zebrafish and other fish species, moderately high basal expres- 
sion levels for the ERs (i.e. $E R \alpha, \beta s$ ) have been recorded in many other non-reproductive organs and tissues, such as the digestive system, muscles, gills, heart, kidney and eyes (Socorro et al. 2000, Pinto et al. 2006, Chandrasekar et al. 2010, Nelson \& Habibi 2013). As has already been extensively reported, the baseline expression patterns of ER $\beta$, which are constitutively expressed at a much higher level in the testes than in the ovaries of zebrafish and other fish species, allows corroboration of the obvious function of ERs $(E R \alpha, \beta s)$ during gametogenesis, and their involvement in the reproductive functions of females and males. In this context, it is appropriate to remember that oestrogens, which are commonly known as 'female hormones' and are studied more and better known during oogenesis, are also key actors in spermatogenesis. In fact, through genomic and nongenomic pathways via ERs $(E R \alpha, \beta s)$, including the pathway to the transmembrane G-protein coupled oestrogen receptors (GPERs), oestrogen receptors participate in reproductive functions. In particular, through the genomic signaling pathway, ERs play a fundamental role in the development, differentiation and maturation of female and male germ cells, as well as in the survival of spermatozoa. Recently, it has also been pointed out that GPER = GPR30 (i.e. a non-genomic pathway) is not necessary for the determination of sex, development or function of the ovary or fertility in female zebrafish (Leal et al. 2009, Schulz et al. 2010, Hao et al. 2013, Nelson \& Habibi 2013, Crowder et al. 2018). Accordingly, the current results and the numerous previous studies allow corroboration of the generalised effects, integrating functions and even autoregulation of ERs (i.e. ERßs vs. $E R \alpha$ ) in both gonads, as well as in different organs and somatic tissues.

Similar to oestrogens, soya isoflavones (i.e. genistein and daidzein), as characteristic phytoestrogens (= 17 $\beta$-oestradiol) or better known as SERMs, can modulate (or interrupt) the gonadal development and reproductive cycle of both sexes (Pelissero et al. 1991, Kiparissis et al. 2003, Patisaul \& Adewale 2009, Lecomte et al. 2017, Xiao et al. 2018). In the present study, baseline ER $\beta$ expression levels decreased significantly in the ovary (but not in the testes) and in the digestive system (including the liver) due to the action of genistein (at $10 \mathrm{mg} \mathrm{l}^{-1}$ ). Conversely, ER $\beta$ expression levels were not altered by the effect of daidzein in either of the gonads. This isoflavone increased ER $\beta$ transcription levels in the head (i.e. brain and pituitary) and in skeletal musculature. In other recent studies, it was reported that both soya isoflavones (at $5 \mathrm{mg} \mathrm{l}^{-1}$ ) increased $\mathrm{ER} \beta$ expression levels in fertilised embryos and newly hatched zebrafish larvae. Nevertheless, during the larval development of Senegalese sole, baseline ER $\beta$ expression levels were modulated in variable ways due to exposure to both isoflavones, showing a greater induction pattern with daidzein (at $20 \mathrm{mg} \mathrm{l}^{-1}$ ) that genistein at lower concentrations (3 and $10 \mathrm{mg} \mathrm{l}^{-1}$; Sarasquete et al. 2017, 2018a, 2019). In a different study, in male and female zebrafish exposed to chemical endocrine disruptors (e.g. diethylstilbestrol and 4-nonylphenol), different transcriptional responses were described for the 3 ERs $(E R \alpha, E R \beta 1, \beta 2)$ in the brain and in both gonads, depending on sex and the circulating basal levels of the natural ligand 17ß-oestradiol (Chandrasekar et al. 2010). Recently, it was noted that ER transcript levels $(E R \alpha, \beta s)$ were not altered in zebrafish males when exposed to bisphenol-A. However, the expression levels of ERs coupled to the transmembrane G protein (GPER-1) were up-regulated by this plasticizer EDC (estrogendendrimer conjugate), which induced apoptotic and epigenetic effects in zebrafish testis (González-Rojo et al. 2019). Taken together, the current results and all the previous findings allow us to corroborate the differential and variable oestrogenic (and anti-) responses that can be induced by different endocrine disruptors, including phytoestrogenic isoflavones, through binding to ERs, as demonstrated in the gonads and other brain and somatic organs and tissues. In particular, a decrease in ER $\beta$ expression levels was observed in the ovary, but not in the testis, due to the action of genistein. In contrast, daidzein did not induce significant transcriptional effects (through ER $\beta$ ), in either of the gonads, which is indicative of differential oestrogenic (anti-) effects of both genistein and daidzein in males and females, since a similar dose of each isoflavone was tested, and the male and female zebrafish were in a similar or parallel state of gonadal maturation.

On the other hand, the highest basal expression levels of HE1 were, surprisingly, expressed in the testes, with only moderate expression levels displayed in the ovaries. The lowest levels of HE1 were recorded in skeletal musculature $>$ head $=$ digestive system. Chakraborty et al. (2017) reported that in Japanese anchovy Engraulis japonicus, some isoforms of the HEs (i.e. AcHEs), which are considered to be ovastacin homologs, predominated both in the ovary and testis, and these isoforms showed no expression biased by sex, suggesting a conserved role in other areas unrelated to sex. In addition, some of these metalloproteases play the role of proteolytic agents by digesting the egg-envelope to facilitate 
penetration of spermatozoa and by promoting interaction between both gametes; other metalloproteases which are within the ovary, such as the alveolin peptidase, do not break the egg-envelope, but are instead involved in its hardening upon fertilisation (Yamagami 1996, Sano et al. 2008, Kawaguchi et al. 2012, Shibata et al. 2012, Nagasawa et al. 2015). Interestingly, in zebrafish, HE1 expression levels were up-regulated by exposure to genistein (at 10 $\mathrm{mg} \mathrm{l}^{-1}$ ) in both male and female gonads, while daidzein only increased HE1 expression levels in skeletal musculature. In a recent study, HE1 reached the highest levels of expression in zebrafish embryos (at $24 \mathrm{~h}$ post-fertilization, hpf), with a decreasing transcriptional pattern from this embryonic phase to hatching (at 72-96 hpf). In addition, expression levels of HE1 increased with exposure to daidzein (at $20 \mathrm{mg} \mathrm{l}^{-1}$, LOTEC - Low Observable Toxic Effect Concentration - value, at $72 \mathrm{hpf}$ ), and this isoflavone accelerated the hatching process in zebrafish, while expression levels of HE1 were not modified by exposure to genistein at $5 \mathrm{mg} \mathrm{l}^{-1}$ (Sarasquete et al. 2018a). In the present study, by inducing increases in HE1 expression levels, genistein (at $10 \mathrm{mg} \mathrm{l}^{-1}$ ) could activate or accelerate degradation of the egg or chorion envelope during the maturation of oocytes and/or increase the process of atresia (for example, autophagy or apoptosis), as described in other species due to increases in HEs (Donato et al. 2003, Chakraborty et al. 2017). Taken together, despite certain increases in the expression levels of HE1 and parallel decreases in ER $\beta$ levels (which are 2 signals oppositely modulated in the ovary [up-down regulations]) with exposure to genistein, these imbalances did not modify histomorphological or histochemical patterns of the vitelline structures, nor did they influence the maturation of the oocytes. Similarly, the expression levels of HE1 also increased in the testes with exposure to genistein, but neither histomorphologicalhistochemical alterations nor effects on the development and maturation of spermatogenic cells were observed.

It is widely known that the BRDT protein has $2 \mathrm{~N}$ terminal bromodomains that bind to the tails of acetylated histones, and thus both bromodomain genes and proteins are involved in epigenetic processes, both constitutive and induced (Bao \& Bedford 2016, Taniguchi 2016). In zebrafish, basal expression levels of BRDT were higher in the ovaries than in the testes, and moderate or low levels of expression were recorded in other organs and tissues (i.e. head, musculature, digestive system). In another recent study, higher levels of BRDT expression were recorded in fertilised eggs of zebrafish, showing lower expression levels during embryogenesis and hatching of larvae (Sarasquete et al. 2018a). In other fish species, such as the protandrous hermaphrodite Sparus aurata, basal levels of the BRDT transcripts were higher in the mature testes than in the ovaries, and moderately high levels of expression were also recorded in other organs and tissues (i.e. brain, pituitary, musculature, heart, kidney, spleen, intestine, gills), while in the gonochoric sea bass Dicentrarchus labrax, similar and elevated expression levels of BRDT were registered in both gonads, and very low levels of expression were recorded in the other organs and tissues. In addition, a constitutive expression of BRDT has been described in both spermatocytes and spermatids, which could be related to the role of BRDT in the termination of meiosis-I as well as in genome condensation or as a transcriptional regulator during these spermatogenetic states (ÚbedaManzanaro et al. 2016). Interestingly, Kurtz et al. (2009) reported that histone acetylation (e.g. H4) occurs during fish spermatogenesis. In the gonochoric species D. labrax, the replacement of histones by protamines was observed during spermiogenesis, while in the hermaphrodite $S$. aurata there was no displacement of these basic nuclear proteins. The inter- and intra-specific differences indicated in BRDT expression levels in different species of fish (including zebrafish in the present study; i.e. higher levels of BRDT in the ovaries than in the testes) suggest a different role of BRDT protein during both spermatogenesis and oogenesis, as a transcriptional regulator and/or for chromatin remodeling and compaction depending on the species, as reported in mammals and fish (Taniguchi 2016, Úbeda-Manzanaro et al. 2016). In the present study, in the zebrafish testes, basal expression levels of BRDT transcripts increased significantly with exposure to daidzein (at $10 \mathrm{mg} \mathrm{l}^{-1}$ ), but not with exposure to the same dose of genistein. In the ovary, no significant transcriptional changes were recorded due to the effect of either isoflavone. In another recent study, baseline expression levels of BRDT were up-regulated by genistein (at $5 \mathrm{mg} \mathrm{l}^{-1}$, LOEC value, at $96 \mathrm{hpf}$ ), but BRDT transcript levels were not altered by exposure to daidzein (up to $20 \mathrm{mg} \mathrm{l}^{-1}$ ), which is known to be less toxic than genistein, as reported in embryos and larvae of zebrafish at LC50 (lethal concentration $50 \%$ ) values of $67.63 \mathrm{mg} \mathrm{l}^{-1}$ (daidzein) and $4.41 \mathrm{mg} \mathrm{l}^{-1}$ (genistein) (Sarasquete et al. 2018a). As previously noted, the BRDT gene and the family of BETs are mainly involved in the modulation of gene transcription through epigenetic mechanisms, between bromo- 
domains and acetylated histones (rich in lysine), regulating genome reprogramming during spermatogenesis and oogenesis, embryogenesis, sex- differentiation and maintenance of lineage commitment (Taniguchi 2016, Úbeda-Manzanaro et al. 2016). Accordingly, in zebrafish, some of the basic and crucial events that participate in certain structural aspects of gametogenesis, and that depend on the regulation and modulation of the bromodomain gene and proteins, would be enhanced by the effect of the phytoestrogenic daidzein, at least at the transcriptional level as demonstrated in mature testicles (i.e. up-regulation of BRDT). Nevertheless, baseline BRDT expression levels were not altered in the ovaries with exposure to both isoflavones. Therefore, despite the induced transcriptional imbalances (up-down regulations) in the expression levels of the studied signals (ER $\beta, H E 1$ and BRDT) in both gonads and in the other organs and tissues, no cellular alterations were observed. In this context, the histomorphological and histochemical characteristics of both gonads (controls and exposed to both isoflavones) are in agreement with numerous previous descriptions and findings. In particular, these gonadal characteristics highlight in the ovary the continuous development and asynchronous growth of germ cells at different stages of oogenesis, which is very characteristic of this species; that is, there is a permanent presence of oogonia, basophilic previtellogenic cells and oocytes in different stages of vitellogenesis and maturation, as well as the presence of post-ovulatory residual follicles and atretic oocytes. In the testis, these characteristics highlight the continuous and synchronous development of cysts of the spermatogenetic cell line, numerous from spermatogonia to spermatozoa, as has been described extensively in zebrafish (Selman et al. 1993, Leal et al. 2009, Gallo \& Costantini 2012, Schulz et al. 2010, Deshpande \& Pancharatna 2013, Lu et al. 2017).

In conclusion, the soya isoflavones genistein and daidzein differentially modulated the basal expression patterns of genes in the gonads of male and female zebrafish. Genistein resulted in a decrease in ER $\beta$ in the ovary but an increase in expression levels of HE1 in both gonads, whereas daidzein only increased the transcript levels of BRDT in the testes. These responses could suggest a greater anti-oestrogenic transcriptional effect (through ER $\beta$ ) in the gonad of females induced by genistein, which also provokes a higher transcriptional choriolytic effect in both gonads. In addition, increased BRDT transcript levels in the testes caused by the action of daidzein could suggest a greater activating effect in spermato- genesis, chromatin remodelling and/or epigenetic processes. Altogether, these transcriptional responses (up-down regulations) must also be complemented and analysed at hormonal and physiological levels, since no histomorphological-histochemical changes were observed in the zebrafish ovary, as recorded through the pattern of distribution of carbohydrates, proteins and the presence of sugar residues in the content of glycoconjugates, which are detected in cortical alveoli, yolk granules and zona radiata of vitellogenic and mature oocytes. Similarly, no appreciable histomorphological or histochemical changes were observed in the spermatogenetic cells (from spermatogonia to spermatozoa). All these transcriptional and cellular responses, as well as changes at the protein, hormonal and enzymatic levels, should be studied in greater depth throughout the reproductive cycle of females and males, as well as during the process of sexual differentiation of zebrafish exposed to both phytoestrogenic isoflavones.

Acknowledgements. This study was financed by Spanish Projects (MINECO-Feder, AGL2014-52906R; RTI2018-0939B-100). Grant contract-CSIC (M.U.M). Our thanks to Mrs. M. Carmen Carmona, Mr Juan A. Canales and Mr. J. Antonio Miquel for the excellent technical assistance.

\section{LITERATURE CITED}

An J, Tzagarakis-Foster C, Scharschmidt TC, Yoshida T, Leitman DC (2001) Estrogen receptor $\beta$-selective transcriptional activity and recruitment of coregulators by phytoestrogens. J Biol Chem 276:17808-17814

Arukwe A, Goksøyr A (2003) Eggshell and egg yolk proteins in fish: hepatic proteins for the next generation: oogenetic, population, and evolutionary implications of endocrine disruption. Comp Hepatol 2:4-21

Arukwe A, Nordtug T, Kortner T, Morensen AS, Brakstad OG (2008) Modulation of steroidogenesis and xenobiotic biotransformation responses in zebrafish (Danio rerio) exposed to water-soluble fraction of crude oil. Environ Res 107:362-370

Asnake S, Modig C, Olsson PE (2019) Species differences in ligand interaction and activation of estrogen receptors in fish and human. J Steroid Biochem Mol Biol 195:105450

Bao J, Bedford MT (2016) Epigenetic regulation of the histone-to-protamine transition during spermiogenesis. Reproduction 151:R55-R70

* Bardet PL, Horard B, Robinson-Rechavi M, Laudet V, Vanacker JM (2002) Characterization of estrogen receptors in zebrafish (Danio rerio). J Mol Endocrinol 28:153-163

*Bennetau-Pelissero C, Breton BB, Bennetau B, Corraze G and others (2001) Effect of genistein-enriched diets on the endocrine process of gametogenesis and on reproduction efficiency of the rainbow trout Oncorhynchus mykiss. Gen Comp Endocrinol 121:173-187

* Berkovits BD, Wolgemuth DJ (2013) The role of the double bromodomain-containing BET genes during mammalian spermatogenesis. Curr Top Dev Biol 102:293-326 
Chakraborty T, Mohapatra S, Tobayama M, Ohta K and others (2017) Hatching enzymes disrupt aberrant gonadal degeneration by the autophagy/apoptosis cell fate decision. Sci Rep 7:31

Chandrasekar G, Archer A, Gustafsson JA, Andersson Lendahl M (2010) Levels of $17 \beta$-estradiol receptors expressed in embryonic and adult zebrafish following in vivo treatment of natural and synthetic ligands. PLOS ONE 5:e9678

Crowder CM, Romano SN, Gorelick DA (2018) G proteincoupled estrogen receptor is not required for sex determination or ovary function in zebrafish. Endocrinology 159:3515-3523

Deshpande PA, Pancharatna K (2013) Oogonial proliferation, oogenesis, folliculogenesis and vitellogenesis in the ovary of zebrafish (Danio rerio): a histological and histochemical analysis. Int J Curr Res 5:1565-1567

* Devlin RH, Nagahama Y (2002) Sex determination and sex differentiation in fish: an overview of genetic, physiological and environmental influences. Aquaculture 208: 191-364

Directive 2010/63/EU of the European Parliament and of the Council of 22 September 2010 on the protection of animals used for scientific purposes. Official Journal of the European Union, L 276/33, The European Parliament and the Council of the European Union

* Donato DM, Hiramatsu N, Arey KM, Hiramatsu K and others (2003) Atresia in temperate basses: cloning of hatching enzyme (choriolysin) homologues from atretic ovaries. Fish Physiol Biochem 28:329-330

Gallo A, Costantini M (2012) Criobiology of reproductive processes in marine animals: state of the art. Mar Drugs 10:2861-2892

González-Rojo S, Lomboc M, Fernández-Díez C, Herraez MP (2019) Male exposure to bisphenol impairs spermatogenesis and triggers histone hyperacetylation in zebrafish testes. Environ Pollut 248:368-379

Hao R, Bondesson M, Singh AV, Riu A and others (2013) Identification of estrogen target genes during zebrafish embryonic development through transcriptomic analysis. PLOS ONE 8:e79020

* Howe K, Clark MD, Torroja CF, Torrance J and others (2013) The zebrafish reference genome sequence and its relationship to the human genome. Nature 496:498-503

Kawaguchi M, Lavoué S, Hiroi J, Nishida M and others (2012) Remarkable consistency of exon-intron structure of hatching enzyme genes and molecular phylogenetic relationships of teleostean fishes. Environ Biol Fishes 94: 567-576

Kim DJ, Seok SH, Baek MW, Lee HY and others (2009) Developmental toxicity and brain aromatase induction by high genistein concentrations in zebrafish embryos. Toxicol Mech Methods 19:251-256

Kimmel CB, Ballard W, Kimmel SR, Ullmann B, Schilling TF (1995) Stages of embryonic development of the zebrafish. Dev Dyn 203:253-310

Kiparissis Y, Hughes R, Metcalfe C, Ternes T (2001) Identification of the isoflavonoid genistein in bleached kraft mill effluent. Environ Sci Technol 35:2423-2427

Kiparissis Y, Balch GC, Metcalfe TL, Metcalfe CD (2003) Effects of the is flavones genistein and equol on the gonadal development of Japanese medaka (Oryzias latipes). Environ Health Perspect 111:1158-1163

Kuiper GGJM, Lemmen JG, Carlsson B, Cotton JC and others (1998) Interaction of estrogenic chemicals and phy- toestrogens with estrogen receptor $\beta$. Endocrinology 139: 4252-4263

Kurtz K, Saperas N, Ausió J, Chiva M (2009) Spermiogenic nuclear protein transitions and chromatin condensation. Proposal for an ancestral model of nuclear spermiogenesis. J Exp Zool B Mol Dev Evol 312B:149-163

*LLeal MC, Cardoso ER, Nobrega RH, Batlouni SR, Bogerd J, França LR, Schulz RW (2009) Histological and stereological evaluation of zebrafish (Danio rerio) spermatogenesis with an emphasis on spermatogonial generations. Biol Reprod 81:177-187

* Lecomte S, Demay F, Ferriére F, Pakdel D (2017) Phytochemical targeting estrogen receptors: Beneficial rather than adverse effects? Int J Mol Sci 18:1381

* Legler J, Broekhof JLM, Brouwer A, Lanser PH and others (2000) A novel in vivo bioassay for (xeno-) estrogens using transgenic zebrafish. Environ Sci Technol 34: 4439-4444

พ Lu H, Cui Y, Jiang L, Ge W (2017) Functional analysis of nuclear estrogen receptors in zebrafish reproduction by genome editing approach. Endocrinology 158: 2292-2308

Mayden RL, Tang KL, Conway WK, Freyhof J and others (2007) Phylogenetic relationships of Danio within the order Cypriniformes: a framework for comparative and evolutionary studies of a model species. J Exp Zool B Mol Dev Evol 308:642-654

Menuet A, Pellegrini E, Andrade I, Blaise O, Laudet V, Kah O, Pakdel F (2002) Molecular characterization of three estrogen receptor forms in zebrafish: binding characteristics, transactivation properties, and tissue distribution. Biol Reprod 66:1881-1892

* Menuet A, Le Page Y, Torres O, Kern L, Kah O, Pakdel F (2004) Analysis of the estrogen regulation of the zebrafish estrogen receptor (ER) reveals distinct effects of ER $\alpha, E R \beta 1$ and ER $\beta 2$. J Mol Endocrinol 32:975-986

* Miyahara M, Ishibashi $H$, Inudo M, Nishijuma H, Iguchi $T$, Guillette LJ Jr, Arizono K (2003) Estrogenic activity of a diet to estrogen receptors $-\alpha$ and $-\beta$ in an experimental animal. J Health Sci 49:481-491

Nagasawa T, Kawaguchi, Sano K, Yasumanu S (2015) Sturgeon hatching enzyme and the mechanism of egg envelope digestion: insight into changes in the mechanism of egg envelope digestion during the evolution of rayfinned fish. J Exp Zool B Mol Dev Evol 324:720-732

Nelson ER, Habibi HR (2013) Estrogen receptor function and regulation in fish and other vertebrates. Gen Comp Endocrinol 192:15-24

Paillisson A, Levasseur A, Gouret P, Cabellaut I, Bontoux M, Pontarotti P, Monget P (2007) Bromodomain testis-specific protein is expressed in mouse oocyte and evolves faster than its ubiquitously expressed paralogogs BRD2, -3 and -4 . Genomics 89:215-223

Patisaul HB, Adewale HB (2009) Long-term effects of environmental endocrine disruptors on reproductive physiology and behavior. Front Behav Neurosci 3:10

Pearse AGE (1985). Histochemistry, theoretical and applied, $4^{\text {th }}$ edn. Churchill Livingstone, Edinburgh

* Pelissero C, Bennetau B, Babin P, Le Menn F, Dunogues J (1991) The estrogenic activity of certain phytoestrogens in the Siberian sturgeon Acipenser baeri. J Steroid Biochem Mol Biol 38:293-299

* Pfaffl MW (2001) A new mathematical model for relative quantification in real-time RT-PCR. Nucleic Acids Res 29:e45 
Piferrer F, Guiguen Y (2008) Fish gonadogenesis. Part II: molecular biology and genomics of sex differentiation. Rev Fish Sci 16:35-55

Pinto PI, Passos AL, Martins RS, Power DM, Canario AVM (2006) Characterization of estrogen receptor $\beta \mathrm{b}$ in seabream (Sparus aurata): phylogeny, ligand-binding and comparative analysis of expression. Gen Comp Endocrinol 145:197-207

Rearick DC, Fleischhaker NT, Kelly MM, Arnold WA, Novak PJ (2014) Phytoestrogens in the environment, I: occurrence and exposure effects on fathead minnows. Environ Toxicol Chem 33:553-559

Reyhanian Caspillo N, Volkova K, Hallgren S, Olsson PE, Porsch-Hällströn I (2014) Short-term treatment of adult male zebrafish (Danio rerio) with $17 \alpha$-ethinyl estradiol affects the transcription of genes involved in development and male sex differentiation. Comp Biochem Physiol C Toxicol Pharmacol 164:35-42

Ribas L, Liew WC, Diaz N, Screenivasan R, Orbán L, Piferrer F (2017) Heat-induced masculinization in domesticated zebrafish is family-specific and yields a set of different gonadal transcriptomes. Proc Natl Acad Sci USA 114: E941-E950

Rocha MJ, Cruzeiro C, Rocha E (2013) Quantification of 17 endocrine disruptor compounds and their spatial and seasonal distribution in the Iberian Ave River and its coastline. Toxicol Environ Chem 95:386-399

Sano K, Inohaya K, Kawaguchi M, Yoshizaki N, Iuchi I, Yasumasu S (2008) Purification and characterization of zebrafish hatching enzyme - an evolutionary aspect of the mechanism of egg envelope digestion. FEBS J 275: 5934-5946

Santos D, Luzio A, Coimbra AM (2017) Zebrafish sex differentiation and gonad development: a review on the impact of environmental factors. Aquat Toxicol 191:141-163

Sarasquete C, Gutierrez M (2005) New tetrachromic VOF stain (VOF III-G.S) for normal and pathological fish tissues. Eur J Histochem 49:211-227

Sarasquete C, González de Canales ML, Piñuela C, MuñozCueto JA and others (2002) Histochemical characteristics of the vitellogenic oocytes of the bluefin tuna, Thunnus thynnus L. Cien Mar 28:419-431

Sarasquete C, Úbeda-Manzanaro M, Ortiz-Delgado JB (2017) Effects of the soya isoflavone genistein in early life stages of the Senegalese sole, Solea senegalensis: thyroid, estrogenic and metabolic biomarkers. Gen Comp Endocrinol 250:136-151

Sarasquete C, Úbeda-Manzanaro M, Ortiz-Delgado JB (2018a) Toxicity and non-harmful effects of the soya isoflavones, genistein and daidzein, in embryos of the zebrafish, Danio rerio. Comp Biochem Physiol C Toxicol Pharmacol 211:57-67

Sarasquete C, Úbeda-Manzanaro M, Ortiz-Delgado JB (2018b) Effects of the soya isoflavone genistein in early life stages of the Senegalese sole, Solea senegalensis: role of the Survivin and proliferation versus apoptosis pathways. BMC Vet Res 14:16

Sarasquete C, Úbeda-Manzanaro M, Ortiz-Delgado JB (2019) Effects of the isoflavone daidzein in Senegalese sole, Soleasenegalensis: modulation of the oestrogen receptor- $\beta$, apoptosis and enzymatic signaling pathways. Histol Histopathol 34:875-887

Sassi-Messai S, Gibert Y, Bernard L, Nishio SI and others
(2009) The phytoestrogen genistein affects zebrafish development through two different pathways. PLOS ONE 4:e4935

Schaaf MJM (2017) Nuclear receptor research in zebrafish. J Mol Endocrinol 59:R65-R76

* Schiller V, Whichmann A, Kriehuber R, Muth-Köhne E, Giesy JP, Hecker M, Fènske M (2013) Studying the effects of genistein on gene expression of fish embryos as an alternative testing approach for endocrine disruption. Comp Biochem Physiol C Toxicol Pharmacol 157:41-53

Schulz RW, de França LR, Lareyre JJ, LeGac F, ChiariniGarcia H, Nobrega RH, Miura T (2010) Spermatogenesis in fish. Gen Comp Endocrinol 165:390-411

* Segner H (2009) Zebrafish (Danio rerio) as a model organism for investigating endocrine disruption. Comp Biochem Physiol C Toxicol Pharmacol 149:187-195

* Segner H, Caroll K, Fenske M, Janssen CR and others (2003) Identification of endocrine-disrupting effects in aquatic vertebrates and invertebrates: a report from the European IDEA project. Ecotoxicol Environ Saf 54:302-314

* Selman K, Wallace RA, Sarka A, Xiaoping QI (1993) Stages of oocyte development in the zebrafish, Brachiodanio rerio. J Morphol 218:203-224

Setchell KD, Clerici C, Lephart ED, Cole SJ and others (2005) S-equol, a potent ligand of estrogen receptor $\beta$, is the exclusive enantiomeric form of the soy isoflavone metabolite produced by human intestinal bacterial flora. Am J Clin Nutr 81:1072-1079

Shibata Y, Iwamatsu T, Suzuki N, Young G and others (2012) An oocyte-specific astacin family protease, alveolin, is released from cortical granules to trigger egg envelope hardening during fertilization in medaka (Oryzias latipes). Dev Biol 372:239-248

* Socorro S, Power DM, Olson PE, Canario AVM (2000) Two estrogen receptors expressed in the teleost fish, Sparus aurata: cDNA cloning, characterization and tissue distribution. J Endocrinol 166:293-306

Spengler P, Korner W, Metzger JW (2001) Substances with estrogenic activity in effluents of sewage treatment plants in southwester Germany. 1. Chemical analysis. Environ Toxicol Chem 20:2133-2141

* Taniguchi Y (2016) The bromodomain and extra-terminal domain (BET) family: functional anatomy of BET paralogous proteins. Int J Mol Sci 17:1849

*Úbeda-Manzanaro M, Ortiz-Delgado JB, Sarasquete C (2016) The bromodomain testis-specific gene (Brdt) characterization and expression in gilthead seabream, Sparus aurata, and European seabass, Dicentrarchus labrax. Eur J Histochem 60:2638

*Wang YQ, Li YW, Chen QL, Liu ZH (2019) Long-term exposure of xenoestrogens with environmental relevant concentration disrupted spermatogenesis of zebrafish through altering sex hormone balance, stimulating germ cell proliferation, meiosis and enhancing apoptosis. Environ Pollut 244:486-494

* Xiao Y, Zhang S, Tong H, Shi S (2018) Comprehensive evaluation of the role of soy and isoflavone supplementation in humans and animals over the past two decades. Phytother Res 32:384-394

* Yamagami K (1996) Studies on the hatching enzyme (choriolysin) and its substrate, egg envelope, constructed of the precursors (choriogenins) in Oryziaslatipes: a sequel to the information in 1991/1992. Zool Sci 13:331-340 